\title{
Inhibition of purple acid phosphatase with $\alpha$-alkoxynaphthylmethylphosphonic acids
}

\author{
Ross P. McGeary ${ }^{\mathrm{a}, \mathrm{b}, *}$, Peter Vella ${ }^{\mathrm{a}}$, Jeffrey Y. W. Mak ${ }^{\mathrm{a}}$, Luke W. Guddat ${ }^{\mathrm{a}}$, Gerhard Schenk ${ }^{\mathrm{a}}$ \\ a The University of Queensland, School of Molecular and Microbial Sciences, Brisbane, Qld 4072, Australia \\ ${ }^{\mathrm{b}}$ The University of Queensland, School of Pharmacy, Brisbane, Qld 4072, Australia
}

\section{A R T I C L E I N F O}

\section{Article history:}

Received 26 September 2008

Revised 27 October 2008

Accepted 28 October 2008

Available online 5 November 2008

\section{Keywords:}

Purple acid phosphatase

PAP

Phosphonate

\begin{abstract}
A B S T R A C T
Purple acid phosphatases (PAPs) are binuclear hydrolases that catalyse the hydrolysis of a range of phosphorylated substrates. Human PAP is a major histochemical marker for the diagnosis of osteoporosis. In patients suffering from this disorder, PAP activity contributes to increased bone resorption and, therefore, human PAP is a key target for the development of anti-osteoporotic drugs. This manuscript describes the design and synthesis of derivatives of 1-naphthylmethylphosphonic acids as inhibitors of PAP. The $K_{\mathrm{i}}$ values of these compounds are as low as $4 \mu \mathrm{M}$, the lowest reported to date for a PAP inhibitor.
\end{abstract}

(c) 2008 Elsevier Ltd. All rights reserved.
Purple acid phosphatase (PAP; E.C. 3.1.3.2) is a binuclear hydrolase that has been isolated from various mammals and plants. ${ }^{1}$ Mammalian PAP is also known as tartrate-resistant acid phosphatase (TRAP) $)^{2}$ or osteoclastic acid phosphatase (OAP). ${ }^{3}$ PAPs catalyse the hydrolysis of phosphorylated substrates under neutral to acidic conditions in vivo, according to the equation: ${ }^{1}$

$\mathrm{RO}-\mathrm{PO}_{3}^{2-}+\mathrm{H}_{2} \mathrm{O} \rightarrow \mathrm{ROH}+\mathrm{HPO}_{4}^{2-}$

The characteristic purple colour of PAP is due to a charge transfer transition between a conserved tyrosine residue and an $\mathrm{Fe}(\mathrm{III})$ in the active site $\left(\lambda_{\max }=510-560 \mathrm{~nm}\right){ }^{4-6}$

Mammalian PAPs are $\sim 35 \mathrm{kDa}$ monomeric proteins with a redox active $\mathrm{Fe}(\mathrm{III})-\mathrm{Fe}(\mathrm{II} / \mathrm{III})$ centre in their active sites. ${ }^{7,8}$ While it is the reduced form that is catalytically active, only the structures of the inactive diferric forms of PAPs from human (hPAP) ${ }^{9}$ and pig (pPAP) ${ }^{10}$ have been determined by X-ray crystallography. In contrast, most plant PAPs are $110 \mathrm{kDa}$ homodimers with redox-inactive $\mathrm{Fe}(\mathrm{III})-\mathrm{Zn}(\mathrm{II})$ or $\mathrm{Fe}(\mathrm{III})-\mathrm{Mn}(\mathrm{II})$ centres. ${ }^{11-13}$ The crystal structures of red kidney bean PAP (rkbPAP) ${ }^{14-16}$ and sweet potato $\mathrm{PAP}^{17}$ have been solved. While the sequence homology between characterised animal and plant PAPs is low, the amino acids in the active site are highly conserved. ${ }^{18}$ In the uninhibited enzyme, the coordination spheres of the two metal ions have an approximate octahedral arrangement with four amino acid ligands and possibly two water molecules per metal

\footnotetext{
* Corresponding author. Tel.: +61 73365 3955; fax: +61 733463249

E-mail address: r.mcgeary@uq.edu.au (R.P. McGeary).
}

centre. ${ }^{1}$ Due to the structural similarity in their catalytically relevant active sites, all PAPs are believed to employ highly conserved mechanistic strategies. ${ }^{1}$

The biological roles of PAPs are diverse and depend on the host organism. Plant PAPs are believed to assist in mobilising organic phosphate esters in soil during germination, ${ }^{19}$ and mammalian PAPs have been linked with iron transport during pregnancy. ${ }^{20}$ Both may be involved in bacterial killing since they are able, at least in vitro, to generate reactive oxygen species (ROS) via Fenton chemistry as a response against pathogens. ${ }^{13,21-24}$ Our interest in PAP as a potential therapeutic target lies in its association with osteoporosis. It is known that PAP is secreted into the bone-resorptive space in mammals, ${ }^{2}$ and PAP activity has long been associated with bone resorption. ${ }^{25}$ In addition, transgenic mice in which the PAP enzyme was over-expressed developed osteoporosis due to increased bone resorption, ${ }^{26}$ whereas the corresponding knockout mice exhibited the opposite condition (osteopetrosis), further implicating the role of PAP in this process, ${ }^{27}$ and establishing PAP as a drug target in the treatment of osteoporosis. ${ }^{28}$

Small anions, including fluoride and tetrahedral oxoanions such as phosphate, vanadate and tungstate are known to inhibit PAP. ${ }^{1,29-31}$ Myers and coworkers ${ }^{32}$ have described a number of simple phosphonates with pendant metal-binding groups, such as thiol, phosphonate and carboxylate, and these have shown inhibitory activity against rkbPAP, in the range 80-3000 $\mu \mathrm{M}$. Phosphotyrosyl-containing tripeptides are excellent substrates for PAP. A number of phosphonate- and carboxylate-containing derivatives of these substrates have been synthesised, and these displayed mid- to low-micromolar inhibitory potency against several mammalian and plant PAPs. ${ }^{28}$ 
Schwender and coworkers ${ }^{3}$ reported the synthesis of a number of derivatives of 1-naphthylmethylphosphonic acid (1) and their inhibitory effects against hPAP. Compound $\mathbf{1}$ was reported to have an $\mathrm{IC}_{50}$ of $30 \mu \mathrm{M}$, whereas no inhibition was detected for its $\alpha$ hydroxy analogue (2). The potencies of these compounds could be increased by the substitution of lipophilic aroyl groups at the $\alpha$-position of $\mathbf{1}$, to give compounds $\mathbf{3}$ and $\mathbf{4}$, with reported $\mathrm{IC}_{50} \mathrm{~S}$ of 6 and $1.4 \mu \mathrm{M}$, respectively. ${ }^{3}$

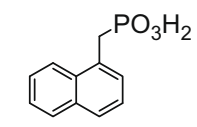

1<smiles>[R]C([R])([R6])c1cccc2ccccc12</smiles>

3, R = 2-naphthoyl, $\mathrm{R}^{1}=\mathrm{H}$

4, $\mathrm{R}=\mathrm{R}^{1}=$ benzoyl

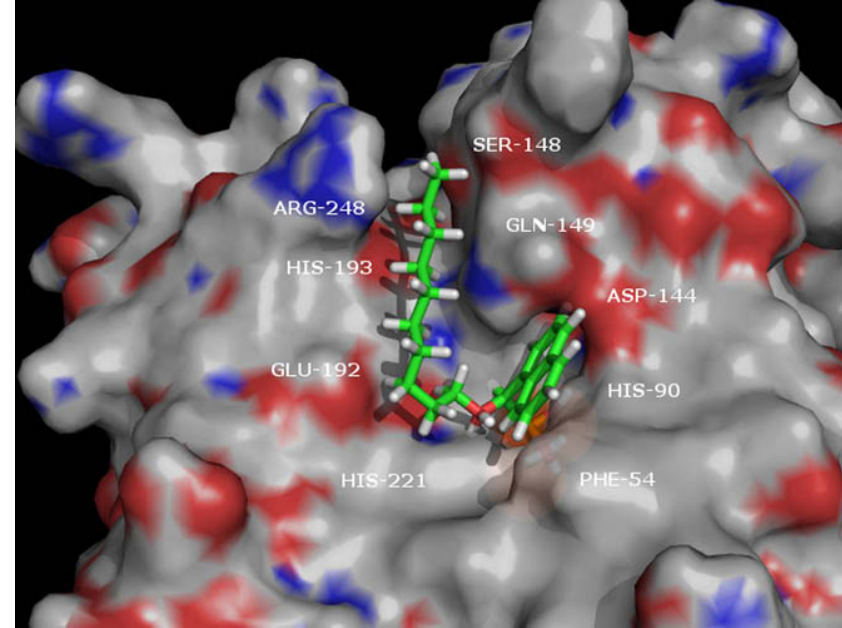

Figure 1. Highest GOLD score docking conformation of the $(R)$-isomer of compound 7 in the active site of hPAP (PDB code $1 \mathrm{WAR}^{9}$ ).

Here, we report the design, synthesis and catalytic effects for a number of new inhibitors of PAP, based on the 1-naphthylmethylphosphonic acid scaffold. rkbPAP and pPAP were used for kinetic studies due to their ready availability and ease of purification. In contrast, hPAP can only be obtained in very small quantities, using a baculoviral recombinant expression system. ${ }^{33}$ The validity of using rkbPAP and pPAP as models of the human enzyme is supported by a number of factors including (i) the high degree of structural conservation in their substrate-binding pockets, ${ }^{9,10,14-16}$ (ii) their conserved reaction mechanism(s), ${ }^{1}$ and (iii) the similarity of inhibition constants for a range of inhibitors reported for several animal (including human) and plant PAPs (e.g., the fluoride inhibition constants of rkbPAP, pPAP and hPAP are 170, 120 and $170 \mu \mathrm{M}$, respectively). ${ }^{1,11,17,28-31}$ Furthermore, mammalian and rkbPAPs have similar catalytic efficiencies and catalyse the hydrolysis of similar substrates. ${ }^{1,11,30}$

Computer modelling was used to identify new compounds that might act as inhibitors of PAPs. In the search for these molecules, naphthalen-1-ylmethyl-phosphonic acid (1) and several of its derivatives were chosen as starting points. The binding orientations of these compounds were assessed by docking them into the hPAP active site ${ }^{9}$ GOLD (Genetic Optimisation for Ligand Docking). ${ }^{34,35}$ The predicted binding orientations of these compounds were examined. As expected, the phosphonate groups bound to the binuclear centre, and a long groove adjacent to the active site was identified as an additional potential point of interaction (see Fig. 1). Hence, the $\alpha$-alkoxy phosphonic acids 5-7 (see below) were designed and docked into the hPAP active site, with the aim that the long alkyl chain would bind in the groove. The docking studies suggested that these modified inhibitors may indeed bind in such a mode to the active site and the adjacent groove. Compounds 5-7 were therefore synthesised as novel candidate PAP inhibitors.

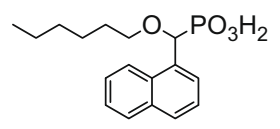

5

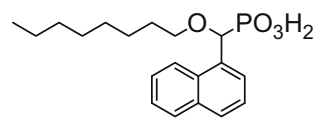

6

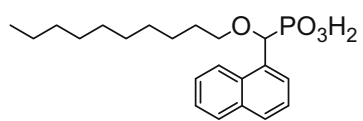

7
The synthetic route to compounds 5-7 is shown in Scheme 1. All compounds were synthesised as racemates. Reaction of 1-naphthaldehyde (8) with diethyl phosphite in the presence of base yielded the $\alpha$-hydroxyphosphonate diester $(\mathbf{9})$. Attempted Williamson etherification of $\mathbf{9}$ with strong base and alkyl iodides surprisingly failed. Treatment of $\mathbf{9}$ with sodium hydride in THF led instead to the formation of the diethyl phosphate ester (10); the product presumably arising via a Brook-type 1,2-rearrangement of the intermediate alkoxide. Indeed, this type of rearrangement has been previously observed in 1-naphthylmethyl systems. ${ }^{36,37}$ Attempts to alkylate $\mathbf{9}$ under milder conditions, using alkyl iodides in the presence of either silver oxide ${ }^{38}$ or bis(tributyltin) oxide $^{39}$ were also unsuccessful, yielding only 1-naphthaldehyde (8) in both cases.

Efforts were then directed towards transforming the hydroxyl group of $\mathbf{9}$ into a leaving group, suitable for displacement with

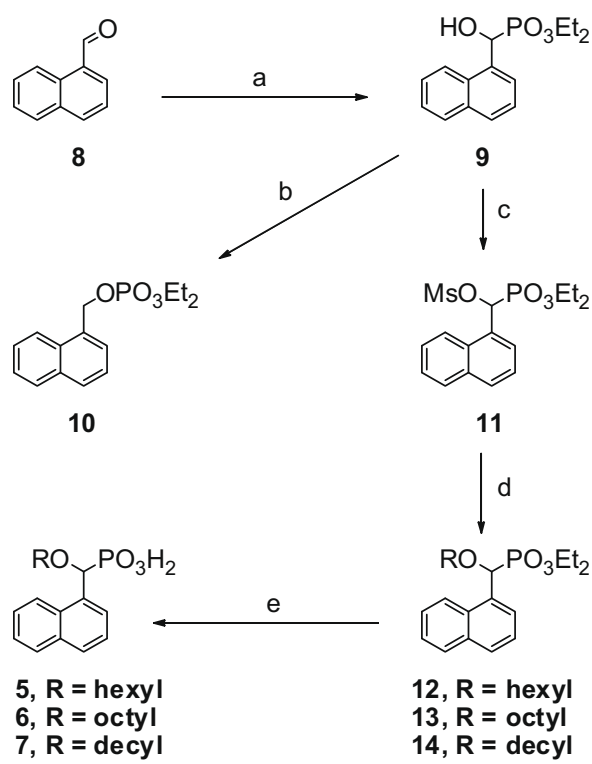

Scheme 1. Reagents and conditions: (a) diethyl phosphite, DIPEA, neat, rt, $17 \mathrm{~h}$ 100\%; (b) NaH, THF, rt, 1 h, 69\%; (c) MsCl, DIPEA, DCM, rt, 3 d, 100\%; (d) ROH, DIPEA MeCN, reflux, 18 h, 68\% (12), 41\% (13), 24\% (14); (e) TMSCl, NaI, MeCN, rt, 18 h, $89 \%$ (5), $100 \%(\mathbf{6}), 66 \%(7)$. 
an alcohol or alkoxide. To that end, $\mathbf{9}$ was converted to its methanesulfonate ester (11) (Scheme 1) which readily underwent substitution with long-chain alcohols in hot acetonitrile in the presence of a base, yielding the desired ethers 12-14. Selective cleavage of the phosphonate ester groups of 12-14, without rupture of the benzylic ether linkage, ${ }^{40}$ was achieved using TMSI, formed in situ from $\mathrm{TMSCl}$ and $\mathrm{NaI}$ in acetonitrile, according to Morita et al., ${ }^{41}$ yielding the final 1-naphthylmethylphosphonic acids 5-7. The same reaction conditions were employed to prepare the $\alpha$-hydroxyphosphonic acid (2) from the corresponding diethyl phosphonic ester (9) (Scheme 2).

The synthesis of 1-naphthylmethylphosphonic acid (1) is shown in Scheme 3. Chloromethylation of naphthalene (15) yielded halide 16, which was subjected to an Arbuzov-type reaction with diethyl phosphite to give 17. Again, we found that Morita's method ${ }^{41}$ successfully dealkylated the diester (17) to give 1, albeit in low yield.

The inhibitory effects of the new compounds were tested with both rkbPAP and pPAP at pH 6.2 and 4.9, the respective $\mathrm{pH}$ opti$\mathrm{ma}^{28,31}$ of the two enzymes (Tables 1 and 2). Hydroxylation of

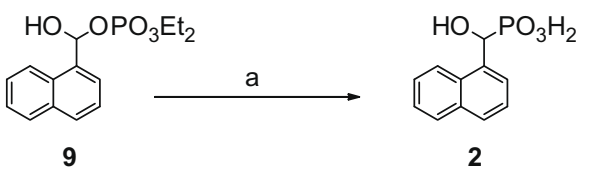

Scheme 2. Reagents and conditions: (a) TMSCl, NaI, MeCN, rt, 3.5 d, 52\%.

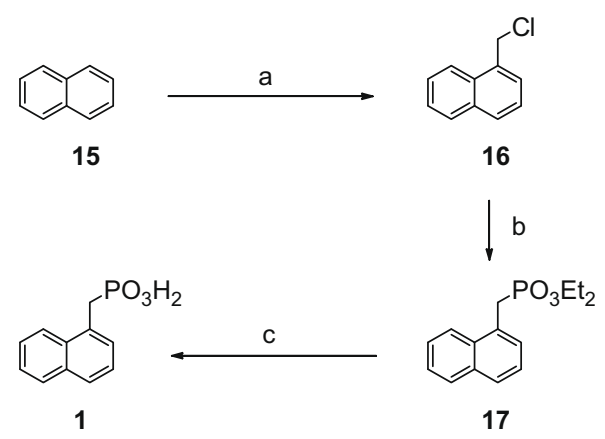

Scheme 3. Reagents and conditions: (a) $\mathrm{CH}_{2} \mathrm{O}, \mathrm{HCl}, \mathrm{H}_{3} \mathrm{PO}_{4}$, $\mathrm{AcOH}$, reflux, $6 \mathrm{~h}, 56 \%$; (b) diethyl phosphite, $\mathrm{Bu}_{4} \mathrm{NI}, \mathrm{K}_{2} \mathrm{CO}_{3}$, DMF, 64 h, 16\%; (c) TMSCl, NaI, MeCN, rt, 16 h, $23 \%$.

Table 1

Kinetic data for inhibitors 1, 2, 5, 6 and $\mathbf{7}$ against rkbPAP at $\mathrm{pH} 6.2$

\begin{tabular}{lllllll}
\hline Inhibitor & $\begin{array}{l}K_{\mathrm{M}} \\
(\mathrm{mM})\end{array}$ & $\begin{array}{l}\mathrm{IC}_{50} \\
(\mathrm{mM})\end{array}$ & $\begin{array}{l}\mathrm{IC}_{50(\text { calc }} \\
(\mathrm{mM})\end{array}$ & $\begin{array}{l}\operatorname{logIC} C_{50} \\
( \pm \operatorname{logSTD})\end{array}$ & $\begin{array}{l}K_{\mathrm{ic}} \\
(\mathrm{mM})\end{array}$ & $\begin{array}{l}K_{\text {iuc }} \\
(\mathrm{mM})\end{array}$ \\
\hline $\mathbf{1}$ & $5.78(24)$ & $>7$ & $\mathrm{ND}$ & $>0.845$ & $\mathrm{ND}$ & $\mathrm{ND}$ \\
$\mathbf{2}$ & $5.31(17)$ & 5 & $\mathrm{ND}$ & 0.700 & $\mathrm{ND}$ & $\mathrm{ND}$ \\
$\mathbf{5}$ & $4.28(54)$ & 1.0 & 1.4 & $0(0.70)$ & $1.47(39)$ & $1.43(30)$ \\
$\mathbf{6}$ & $3.41(42)$ & 0.1 & 0.09 & $-1(2.15)$ & $0.05(1)$ & $0.129(30)$ \\
$\mathbf{7}$ & $3.10(18)$ & 0.008 & 0.01 & $-2.10(3.50)$ & $0.0040(7)$ & $0.03(1)$ \\
\hline
\end{tabular}

$K_{\mathrm{M}}$, Michaelis constant.

$K_{\mathrm{ic}}$, Competitive inhibition constant.

$K_{\text {iuc }}$, Uncompetitive inhibition constant.

$\mathrm{IC}_{50 \text { (calc), }} K_{\mathrm{i}}$ and $\mathrm{IC}_{50}$ values are correlated via the following equation: ${ }^{43}$

$I C_{50}=\frac{K_{M}+[S]}{\left(\frac{[S]}{K_{\text {luc }}} \frac{K_{M}}{K_{\text {Ic }}}\right)}$

ND, not determined.
Table 2

Kinetic data for inhibitors $\mathbf{1}, \mathbf{2}, \mathbf{5}, \mathbf{6}$ and $\mathbf{7}$ against pig PAP at pH 4.9

\begin{tabular}{lllllll}
\hline Inhibitor & $\begin{array}{l}K_{\mathrm{M}} \\
(\mathrm{mM})\end{array}$ & $\begin{array}{l}\mathrm{IC}_{50} \\
(\mathrm{mM})\end{array}$ & $\begin{array}{l}\mathrm{IC}_{50(\text { calc })} \\
(\mathrm{mM})\end{array}$ & $\begin{array}{l}\log \mathrm{IC}_{50} \\
( \pm \operatorname{logSTD})\end{array}$ & $\begin{array}{l}K_{\text {ic }} \\
(\mathrm{mM})\end{array}$ & $\begin{array}{l}K_{\text {iuc }} \\
(\mathrm{mM})\end{array}$ \\
\hline $\mathbf{5}$ & $2.65(34)$ & 0.43 & $\mathrm{ND}$ & $-0.37(1.70)$ & $\mathrm{ND}$ & $\mathrm{ND}$ \\
$\mathbf{6}$ & $1.50(20)$ & 0.03 & 0.04 & $-1.5(3)$ & $0.023(8)$ & $0.044(9)$ \\
$\mathbf{7}$ & $1.13(11)$ & 0.02 & 0.02 & $-1.70(3.50)$ & $0.017(3)$ & $0.020(4)$ \\
\hline
\end{tabular}

the benzylic carbon of $\mathbf{1}$, to give compound $\mathbf{2}$, had very little effect on the binding affinity. Since the estimated $\mathrm{IC}_{50}$ was $\sim 5 \mathrm{mM}$ the $K_{\mathrm{i}}$ values are expected to be large $(>5 \mathrm{mM})$ and were thus not determined. However, the addition of an alkyl chain to the hydroxylated phosphonate derivative led to a substantial increase in binding affinity. The critical length required to observe a significant effect is six carbon atoms; although the 'hexyl' derivative $\mathbf{5}$ is still only weakly binding, the 'octyl' derivative $\mathbf{6}$ displayed a 10-fold reduction in $\mathrm{IC}_{50}$ value for rkbPAP (Table 1 ). A further elongation of the chain to ten carbon atoms ('decyl' derivative') led to another dramatic reduction in the $\mathrm{IC}_{50}$ value to $\sim 8 \mu \mathrm{M}$. These observations are in good agreement with the in silico docking study (see above), which indicates that the predicted binding mode of the phosphonate compounds involves interactions with a groove in the vicinity of the binuclear active site.

For the 'hexyl'-, 'octyl'- and 'decyl'-derivatives (compounds $\mathbf{5}$, 6 and 7 respectively), $K_{\mathrm{i}}$ values were measured to determine the mode of interactions between the enzyme and inhibitor (Table 1 ). As anticipated, the $K_{\mathrm{i}}$ values are in reasonable agreement with the $\mathrm{IC}_{50}$ values. The compounds inhibit the catalytic reaction in a noncompetitive or mixed competitive mode, indicating that they bind to both the free enzyme and the enzyme-substrate (ES) complex (see Figure S1 in the Supplementary Section). $K_{\text {ic }}$ and $K_{\text {iuc }}$ represent the inhibitor dissociation constants (inhibition constants) for the free enzyme and ES complex. If $K_{\mathrm{ic}} \sim K_{\mathrm{iuc}}$ the inhibition mode is noncompetitive, if $K_{\mathrm{ic}} \neq K_{\mathrm{iuc}}$ it is of mixed type. ${ }^{42}$ For rkbPAP the two inhibition constants for the 'hexyl'derivative $\mathbf{5}$ are similar (noncompetitive inhibition), and as the chain length increases both constants become smaller (indicating increased binding affinity of the inhibitor), but $K_{\mathrm{ic}}$ becomes dominant. In case of the 'decyl'-derivative $\mathbf{7}$, the inhibitor binds approximately sevenfold tighter to the free enzyme than the ES complex ( $4 \mu \mathrm{M}$ vs $30 \mu \mathrm{M}$, respectively, for rkbPAP, Table 1 ) The $\mathrm{IC}_{50}$ of a particular inhibitor can be calculated from the above $K_{\mathrm{i}}$ values. ${ }^{43}$ In general, there is good agreement between these calculated $\mathrm{IC}_{50}$ values and the experimentally determined ones (Table 1). Compound $\mathbf{7}$ is to date the most potent PAP inhibitor of those tested, and its high water solubility makes it a promising candidate as a clinical lead.

The phosphonate derivatives (5-7) have a similar inhibitory effect on pPAP (Table 2). In terms of the $\mathrm{IC}_{50}$ values a similar trend as the one observed for the rkbPAP enzyme has been observed, that is, the longer the alkyl chain the more potent the inhibitor. However, in contrast to the plant PAP the 'hexyl'derivative $\mathbf{5}$ is already a good inhibitor of the pig enzyme with an $\mathrm{IC}_{50}$ value of $0.43 \mathrm{mM}$.

In conclusion, we have used computer-aided inhibitor design to identify a family of $\alpha$-alkoxynaphthylmethylphosphonic acids as potent inhibitors of PAPs. These compounds were synthesised and assayed with rkbPAP and pPAP. Compound 7 was found to be the most active, with an $\mathrm{IC}_{50}$ value of $20 \mu \mathrm{M}$ in pPAP and $8 \mu \mathrm{M}$ in rkbPAP. These compounds are currently being used in crystallisation trials to form complexes with mammalian and plant PAPs. Future work will address the inhibitory activities of the individual enantiomers of each inhibitor. The results of these studies will provide the basis for the next round of rational drug design. 


\section{Acknowledgments}

We thank Dr. Tri Le for assistance with NMR studies, Mr. Graham MacFarlane for MS measurements. This work was funded by a grant from the Australian Research Council (DP0986292).

\section{Supplementary data}

Supplementary data associated with this article can be found, in the online version, at doi:10.1016/j.bmcl.2008.10.125.

\section{References and notes}

1. Mitić, N.; Smith, S. J.; Neves, A.; Guddat, L. W.; Gahan, L. R.; Schenk, G. Chem. Rev. 2006, 106, 3338

2. Oddie, G. W.; Schenk, G.; Angel, N. Z.; Walsh, N.; Guddat, L. W.; de Jersey, J.; Cassady, A. I.; Hamilton, S. E.; Hume, D. A. Bone 2000, 27, 575.

3. Schwender, C. F.; Beers, S. A.; Malloy, E.; Demarest, K.; Minor, L.; Lau, K. H. W. Bioorg. Med. Chem. Lett. 1995, 5, 1801.

4. Antanaitis, B. C.; Aisen, P.; Lilienthal, H. R. J. Biol. Chem. 1983, 258, 3166.

5. Averill, B. A.; Davis, J. C.; Burman, S.; Zirino, T.; Sanders-Loehr, J.; Loehr, T. M.; Sage, J. T.; Debrunner, P. G. J. Am. Chem. Soc. 1987, 109, 3760.

6. Yang, Y.-S.; McCormick, J. M.; Solomon, E. I. J. Am. Chem. Soc. 1997, 119, 11832.

7. Wang, D. L.; Holz, R. C.; David, S. S.; Que, L., Jr.; Stankovich, M. T. Biochemistry 1991, 30, 8187

8. Bernhardt, P. V.; Schenk, G.; Wilson, G. J. Biochemistry 2004, 43, 10387.

9. Sträter, N.; Jasper, B.; Scholte, M.; Krebs, B.; Duff, A. P.; Langley, D. B.; Han, R.; Averill, B. A.; Freeman, H. C.; Guss, J. M. J. Mol. Biol. 2005, 351, 233.

10. Guddat, L. W.; McAlpine, A. S.; Hume, D.; Hamilton, S.; de Jersey, J.; Martin, J. L. Structure 1999, 7, 757.

11. Beck, J. L.; McConachie, L. A.; Summors, A. C.; Arnold, W. N.; de Jersey, J.; Zerner, B. Biochim. Biophys. Acta 1986, 869, 61

12. Schenk, G.; Ge, Y.; Carrington, L. E.; Wynne, C. J.; Searle, I. R.; Carroll, B. J.; Hamilton, S.; de Jersey, J. Arch. Biochem. Biophys. 1999, 370, 183.

13. Leung, E.; Teixeira, M.; Guddat, L. W.; Mitić, N.; Schenk, G. Curr. Topics Plant Biol. 2007, 8, 21.

14. Sträter, N.; Klabunde, T.; Tucker, P.; Witzel, H.; Krebs, B. Science 1995, 268, 1489.

15. Klabunde, T.; Sträter, N.; Fröhlich, R.; Witzel, H.; Krebs, B. J. Mol. Biol. 1996, 259, 737.
16. Schenk, G.; Elliott, T. W.; Leung, E. W. W.; Mitić, N.; Carrington, L. E.; Gahan, L. R.; Guddat, L. W. BMC Struct. Biol. 2008, 8, 6.

17. Schenk, G.; Gahan, L. R.; Carrington, L. E.; Mitić, N.; Valizadeh, M.; Hamilton, S. E.; de Jersey, J.; Guddat, L. W. Proc. Nat. Acad. Sci. U.S.A. 2005, 102, 273.

18. Schenk, G.; Guddat, L. W.; Ge, Y.; Carrington, L. E.; Hume, D. A.; Hamilton, S.; de Jersey, J. Gene 2000, 250, 117.

19. Cashikar, A. G.; Kumaresan, R.; Rao, N. M. Plant Physiol. 1997, 114, 907.

20. Nuttleman, P. R.; Roberts, R. M. J. Biol. Chem. 1990, 265, 12192.

21. Bozzo, G. G.; Raghothama, K. G.; Plaxton, W. C. Eur. J. Biochem. 2002, 269, 6278.

22. Sibille, J. C.; Doi, K.; Aisen, P. J. Biol. Chem. 1987, 262, 59.

23. Räisänen, S. R.; Alatalo, S. L.; Ylipahkala, H.; Halleen, J. M.; Cassady, A. I.; Hume, D. A.; Väänänen, H. K. Biochem. Biophys. Res. Commun. 2005, 331, 120.

24. Kaija, H.; Alatalo, S. L.; Halleen, J. M.; Lindqvist, Y.; Schneider, G.; Väänänen, H. K.; Vihko, P. Biochem. Biophys. Res. Commun. 2002, 292, 128.

25. Susi, F. R.; Goldhaber, P.; Jennings, J. M. Am. J. Physiol. 1966, 211, 959.

26. Angel, N. Z.; Walsh, N.; Forwood, M. R.; Ostrowski, M. C.; Cassady, A. I.; Hume, D. A. J. Bone Miner. Res. 2000, 15, 103.

27. Hayman, A. R.; Jones, S. J.; Boyde, A.; Foster, D.; Colledge, W. H.; Carlton, M. B.; Evans, M. J.; Cox, T. M. Development 1996, 122, 3151.

28. Valizadeh, M.; Schenk, G.; Nash, K.; Oddie, G. W.; Guddat, L. W.; Hume, D. A.; de Jersey, J.; Burke, T. R.; Hamilton, S. Arch. Biochem. Biophys. 2004, 424, 154.

29. Funhoff, E. G.; De Jongh, T. E.; Averill, B. A. J. Biol. Inorg. Chem. 2005, 10, 550.

30. Mitić, N.; Valizadeh, M.; Leung, E. W. W.; de Jersey, J.; Hamilton, S.; Hume, D. A.; Cassady, A. I.; Schenk, G. Arch. Biochem. Biophys. 2005, 439, 154.

31. Elliott, T. W.; Mitić, N.; Gahan, L. R.; Guddat, L. W.; Schenk, G. J. Braz. Chem. Soc. 2006, 17, 1558.

32. Myers, J. K.; Antonelli, S. M.; Widlanski, T. S. J. Am. Chem. Soc. 1997, 119 3163.

33. Marshall, K.; Nash, K.; Haussman, G.; Cassady, I.; Hume, D.; de Jersey, J.; Hamilton, S. Arch. Biochem. Biophys. 1997, 345, 230.

34. Jones, G.; Willett, P.; Glen, R. C. J. Mol. Biol. 1995, 245, 43.

35. Jones, G.; Willett, P.; Glen, R. C.; Leach, A. R.; Taylor, R. J. Mol. Biol. 1997, 267 727.

36. Kimura, M.; Kurata, T.; Yamashita, T.; Kawai, H.; Sawaki, Y. Electrochim. Acta 1997, 42, 2225.

37. ElKaim, L.; Gaultier, L.; Grimaud, L.; Dos Santos, A. Synlett 2005, 2335.

38. Ramza, J.; Zamojski, A. Carbohydr. Res. 1992, 228, 205

39. David, S.; Hanessian, S. Tetrahedron 1985, 41, 643.

40. Olah, G. A.; Narang, S. C.; Gupta, B. G. B.; Malhotra, R. J. Org. Chem. 1979, 44, 1247.

41. Morita, T.; Okamoto, Y.; Sakurai, H. Tetrahedron Lett. 1978, 19, 2523.

42. Segel, I. H. Enzyme Kinetics: Behavior and Analysis of Rapid Equilibrium and Steady-State Enzyme Systems; John Wiley and Sons, Inc: New York, 1993.

43. Cheng, Y.-C.; Prusoff, W. H. Biochem. Pharmacol. 1973, 22, 3099. 